\title{
Addressing the Needs of Children With Disabilities Experiencing Disaster or Terrorism
}

\author{
Laura M. Stough ${ }^{1}$ Elizabeth McAdams Ducy ${ }^{2} \cdot$ Donghyun Kang ${ }^{1}$
}

(C) Springer Science+Business Media New York 2017

\begin{abstract}
Purpose of Review This paper reviews the empirical literature on psychosocial factors relating to children with disabilities in the context of disaster or terrorism.

Recent Findings Research indicates adults with disabilities experience increased exposure to hazards due to existing social disparities and barriers associated with disability status. However, studies on the psychological effects of disaster/terrorism on children with pre-existing disabilities are exceedingly few and empirical evidence of the effectiveness of trauma-focused therapies for this population is limited. Secondary adversities, including social stigma and health concerns, also compromise the recovery of these children post-disaster/terrorism. Schools and teachers appear to be particularly important in the recovery of children with disabilities from disaster. Disasters,
\end{abstract}

This article is part of the Topical Collection on Child and Family Disaster Psychiatry

Laura M. Stough

lstough@tamu.edu

Elizabeth McAdams Ducy

ducy@sonoma.edu

Donghyun Kang

junsr30@tamu.edu

1 Department of Educational Psychology, Center on Disability and Development, Texas A\&M University, Mail Stop 4225, College Station, TX 77843, USA

2 Department of Educational Leadership and Special Education, School of Education, Sonoma State University, 1801 East Cotati Ave, Rohnert Park, CA 94928, USA terrorism, and war all contribute to increased incidence of disability, as well as disproportionately affect children with pre-existing disabilities.

Summary Disaster preparedness interventions and societal changes are needed to decrease the disproportionate environmental and social vulnerability of children with disabilities to disaster and terrorism.

Keywords Disaster · Disability · Children · Terrorism · Trauma $\cdot$ Mental health

\section{Introduction}

Emerging research suggests that disasters and terrorist acts have differential, and most often negative, consequences for individuals with disabilities. Studies emanating from a range of academic disciplines report barriers and adverse outcomes for people with disabilities during emergency evacuation, sheltering, and recovery [1-4]. Epidemiological studies also indicate higher exposure and mortality rates for people with disabilities in some disasters [5, 6]. Similarly, studies find children more physically and psychologically vulnerable in emergency situations [7-9]. Children with disabilities may need additional assistance to evacuate and to take shelter, as well as experience compromised physical or mental health following disaster [10]. However, while the effects of disaster and, to a lesser degree, terrorism have been well-researched in child and adolescent populations, little of that research has focused on the experi-

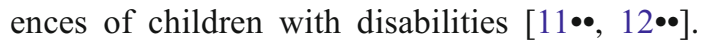

The purpose of this article is to present implications derived from empirical literature for researchers and practitioners addressing the psychological recovery of children 
with disabilities affected by disaster or terrorism. Due to the exceedingly small amount of studies conducted on children with disabilities, this review extrapolates from research both on adults with disabilities and on children without disabilities who have experienced disaster or terrorism.

\section{Disability Definition and Prevalence}

Mental health researchers use criteria from the Diagnostic and Statistical Manual [13] to diagnose populations with cognitive and psychological disabilities. In the broader research literature, functioning and disability are conceptualized as the result of a dynamic interaction between health conditions and personal and environmental factors [14]. The disability label is thus extended by researchers to also refer to participants with sensory, mobility, and health disabilities.

Depending on the definition and source of data, the estimated number of children with disabilities under the age of 18 in the world ranges between 93 and 150 million [15]. Disability is correlated with higher poverty rates and reduced access to health care; therefore, disability prevalence can be predicted to be higher in less affluent communities both in the USA [16] and in countries throughout the world [17].

\section{Exposure and Vulnerability to Disasters and Terrorism}

Individual response to disaster and terrorism is often linked to severity of exposure, referred to as the "dose-response gradient," in which psychological symptoms or illnesses are related to greater cumulative exposure to these experiences $[9,18]$. Research consistently finds dose responses in children exposed to disasters or terrorism, with those experiencing more intense or severe trauma expressing the most psychological impact [19-22].

Research on individuals with disabilities reports this group experiences increased exposure to hazards. People with blindness or hearing impairments experience difficulties receiving emergency communications [3, 23]. People with mobility disabilities encounter barriers during evacuation and transportation [24, 25], while people with health-related disabilities have difficulties obtaining medical support post-disaster [4, 26].

Children with disabilities are believed to experience amplified exposure to disasters due to increased psychological,

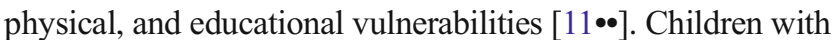
disabilities are more exposed to traumatic life events, such as death, illness, and violence, than their peers [27, 28]. Family demographics such as income, employment, and parent education also contribute to disaster exposure in children [29]. Families which include a member with a disability have among the highest poverty rates, lowest educational levels, and lowest incomes of all households in the USA [16]. Worldwide, children with disabilities are more likely to live in poverty, to not complete school, and to have poorer health than children without disabilities [17, 30, 31]. In addition, following disasters or conflict, children with disabilities are less likely to receive appropriate psychological, medical, and rehabilitative services [31, 32]. Finally, school emergency plans often do not incorporate the needs of students with disabilities during disaster or terrorism [33].

\section{Disability-Related Factors Which May Influence Exposure}

\section{Cognitive and Emotional Factors}

Some cognitive or emotional disabilities may make children more vulnerable to disaster or terrorism exposure. For example, children with ADHD may be less capable of paying attention to instructions during evacuations, while children with autism may have difficulties when encountering unusual and unexpected stimuli, such as often occur in emergency situations. Lower literacy and educational levels may affect children's understanding of dangerous situations [34]. In addition, cognitive capacity and developmental stage influence children's threat appraisal, attention, and concentration [35].

Cognitive factors also influence children's reactions to disasters and terrorism and these reactions similarly can vary given developmental levels or cognitive abilities [35]. Preevent emotional status and prior trauma also affect post-disaster/terrorism reactions and recovery in children [20,36] and several studies report the development of post-traumatic stress disorder (PTSD) in children is strongly related to pre-disaster general mental health $[37,38]$. For children with pre-existing mental illness, it can be hypothesized that PTSD post-disaster/ terrorism will be more likely, especially when PTSD symptoms are shared with symptoms of the pre-existing mental illness. However, to date, studies have not closely examined how pre-existing cognitive disability affects reactions to disasters or terrorism [39•].

\section{Health Factors}

Some children with disabilities have medical conditions, specialized diets, or use adaptive equipment which can complicate evacuation and treatment in emergency situations [40, 41]. Pre-existing health disabilities have also been linked to increased mortality in earthquakes [5]. Public health research on the level and types of emergency preparedness by adults with disabilities has found mixed results [42, 43]. Similarly, 
studies on families with children with health care needs find varying levels of emergency preparedness [40, 44]. Low levels of emergency preparedness are likely to increase the dose exposure that children with special health care needs will have to disasters and terrorist acts.

Pre-existing chronic health conditions are also linked with elevated adverse health concerns post-disaster. A crosssectional study of 531 children and adolescents with and without chronic conditions was conducted immediately following Hurricane Katrina [45•]. Children with chronic conditions sought care more often for new health problems post-disaster. In addition, children with the pre-existing conditions of diabetes or asthma were more likely to seek medical care postdisaster, to run out of medications, or to miss a physician visit due to the hurricane.

\section{Physical and Sensory Factors}

Research on children with physical or sensory disabilities, including blindness or hearing impairments, has not been forthcoming. However, research reports that adults with mobility impairments encounter considerable barriers in evacuation and sheltering which could lead to increased exposure to disasters or terrorist attacks [25, 46]. Research on adults who were deaf or with hearing impairments reported problems with receiving emergency communications, in addition to difficulties during evacuation and sheltering $[47,48]$. A study of older adults with visual impairments reported concerns related to evacuation, orientation, and mobility, as well as communication during an earthquake [3].

\section{Reactions of Children With Disabilities to Disaster and Terrorism}

\section{Post-Traumatic Stress Disorder}

As disability status is associated with an increased risk of exposure, psychological effects are likely to be both higher and more severe for individuals with disabilities post-disaster/terrorism. However, only two studies have clinically examined the mental health of children with pre-existing disabilities. In the first of these studies, children and adolescents with autism spectrum disorder were clinically assessed and 12 $(17.4 \%)$ out of $18(26.1 \%)$ participants with trauma history were clinically diagnosed with PTSD [49•]. Psychiatric examination towards PTSD diagnosis was made using the Schedule for Affective Disorders and Schizophrenia for School Age Children-Present and Lifetime Version, Posttraumatic Stress Disorder scale (K-SADS-PL, PTSD scale) using parents and, when possible, participants as informants. Witnessing or being a victim of an accident, disaster, violence, physical abuse, and/or sexual abuse were the sources of trauma. Symptoms observed, in addition to those related to PTSD, were aggressiveness, distractibility, sleep disturbances, agitation, and regression in social interactions. In a second study, PTSD after exposure to terror attacks was investigated in 56 adolescents with learning disabilities (LD) and compared with 48 nonclinical controls [50•]. Significantly higher PTSD scores were found in the LD group than in the controls, even while controlling statistically for levels of exposure to witnessing of terror attacks. The researchers argued that LD hinders coping with traumatic events through interference with encoding and processing of information - both cognitive mechanisms through which meaning is constructed about a traumatic event [50•]. Together, these two studies provide the strongest clinical evidence for PTSD in children with autism spectrum disorder and LD, however, research specific to PTSD in children with sensory, health, mobility-related, or mental illness disabilities has not been forthcoming.

Research on adults with pre-existing psychiatric illness suggests that they may experience a higher incidence of PTSD post-disaster; however, studies also suggest that continuity of psychological treatment impedes exacerbation of existing mental illness as well as the occurrence of new psychiatric disorders unrelated to PTSD symptomatology [39•]. Due to a scarcity of literature, it is unknown if this mechanism also applies to children with disabilities.

Careful attention is needed to distinguish presentation of PTSD from behaviors commonly associated with some childhood disabilities. In particular, PTSD and other psychiatric disorders can present differently in individuals with intellectual disabilities and behaviors such as aggression, anger outbursts, self-injuries, and non-compliance can be symptoms of PTSD in this population [51, 52•]. Individuals with intellectual disabilities also have a higher risk of PTSD due to previous trauma exposure of various types, including sexual trauma and physical abuse [61]. The Diagnostic Manual-Intellectual Disability (DM-ID-2) can assist clinicians in distinguishing between typical behaviors in people with intellectual and developmental disabilities and those that indicate a psychiatric disorder [51].

\section{Grief and Loss}

Only a couple of studies report children's grief reactions to disaster- or terrorism-related loss. A sample of 121 children who lost their fathers during the 11 September 2001 terrorist attacks were followed over a 5-year period while receiving psychological services [52•]. Four children with learning disabilities who were part of the sample displayed a range of grieving behaviors, including withdrawal and emotional outbursts. When compared to their peers, these children displayed less intrusive grieving behaviors as well as a later onset of trauma-related behaviors [52•]. In a second study, children with significant disabilities expressed emotional reactions to 
the loss of housing and personal possessions as a result of Hurricane Ike [53•]. These two studies, however, had small samples and provided behavioral descriptions rather than clinical diagnoses of these children with disabilities. Sormanti and Ballan [54] provide some recommendations on interventions for grieving children with developmental disabilities exposed to trauma. For example, clinicians can support understanding of loss in children with developmental disabilities through providing concrete verbal explanations or using pictures to illustrate the concept of death.

\section{Behavioral Responses}

Collectively, studies available on children with pre-existing disabilities consistently report behavioral change post-disaster/terrorism $[45 \bullet, 49 \bullet, 50 \bullet, 52 \bullet, 53 \bullet, 55 \bullet, 56 \bullet$. In the Valenti et al. study [56•] of 18 children and adolescents with autism spectrum disorder, participants displayed significant declines in adaptive behavior during the first months following the 2009 L'Aquila earthquake in Italy. Communication, socialization skills, and daily living skills decreased post-disaster and had not yet returned to baseline a full year following the earthquake. An older, yet relevant, study [55•] clinically assessed 162 children both before and following the 1988 Bangladesh flood disaster. Forty-nine of these children were diagnosed with either a cognitive, motor, hearing, vision, or seizurerelated disability. A significant increase in problems with enuresis and aggression was found in one-third (30.2\%) of the sample. However, no behavioral differences were found between children with and without disabilities nor between male and female children. However, the study did not distinguish between disaster and other precipitating traumas, such as sexual abuse. In another study, parents of children with chronic conditions were more likely to report negative psychological changes in their children post-disaster, specifically higher levels of sadness and withdrawal, and behavioral changes [45•], but these reports were not clinically verified. Attention to behavioral changes in children with disabilities is warranted post-disaster/terrorism as pre-existing behaviors may have been exacerbated but not indicative of new diagnoses. In addition, children receiving special education services often have behavioral plans requiring intensive interventions, and the loss of these records during emergency situations can cause a break in services to students with disabilities [11••].

\section{Individual Psychological Treatment of Children With Disabilities}

\section{Diagnostic Overshadowing}

Diagnostic overshadowing can hinder accurate identification of psychopathology and grief in individuals with disabilities post-trauma [51, 57]. For example, if a child with autism demonstrates an increase in stereotypical behaviors after experiencing a disaster, clinicians may attribute these symptoms to the pre-existing disability, not to trauma exposure. Gathering a complete trauma history and descriptions of child conduct from caregivers can help clinicians distinguish between typical behavior and possible trauma symptoms in children with disabilities. Parents are often the source of the best information for a child with disabilities [11••]. However, limited parental functioning post-disaster may impede recognition of trauma symptoms in their own children [22].

\section{Cognitive-Behavioral Therapies}

Trauma-focused cognitive-behavioral therapies (TFCBT) have strong empirical support and is considered a front line treatment for child trauma [58]. However, Ramirez de Arellano and colleagues [59] found that children with intellectual disabilities, developmental disabilities, and serious mental illness have been largely excluded from studies on trauma-focused CBT: empirical evidence for its effectiveness in these populations is thus limited. However, some studies have demonstrated that CBT is successful in treating common mental health problems including anxiety, OCD, or depression in children with autism of normal intelligence [60]. Children with intellectual disabilities, however, may have difficulty with cognitively reprocessing events [10] as well as impairments in receptive and expressive language which may hinder involvement with CBT interventions [61]. Some studies have shown that adults with mild to moderate intellectual disabilities benefit from CBT to treat psychological illnesses such as depression [62] but adaptations to traditional CBT methods may be needed [63]. While CBT adaptations for children with autism have been developed [60], increased investigation into the use of CBT with children with intellectual disabilities or language limitations is warranted.

\section{Pharmapsychology}

Individuals with disabilities often have additional medical conditions making a comprehensive medical evaluation essential when prescribing medication post-trauma [61]. A few studies report on the use of medication, as a part of a comprehensive intervention, to treat PTSD in adults with intellectual disabilities (see [61] for a review); however, pharmapsychology use with children with disabilities impacted by disaster or terrorism has not been investigated. In addition, the use of medication as a sole method to treat challenging behaviors in individuals with developmental disabilities does not have an established efficacy base $[62,64]$. The use of medications with children exposed to 
disaster or terrorism should be adjunctive to psychotherapeutic interventions and used only to relieve specific acute symptoms [65].

\section{Reactions of Families of Children With Disabilities to Disaster and Terrorism}

\section{Parent-Child Relationships Post-Disaster/Terrorism}

Parents are the most important source of emotional support for children after emergency experiences [29]. On the other hand, children can be negatively affected by parents' distress or poor coping strategies in disaster contexts $[9,20,66]$. Some parents of children with disabilities report greater parenting stress than do parents of other children [28,67] and may become even more overwhelmed post-disaster given the greater support needs of children with disabilities [11••, 66]. In addition, the quality of the pre-existing parent-child relationship may affect psychological outcomes post-disaster/terrorism. Finzi-Dottan et al. [50•] found that adolescents with learning disabilities who had secure attachment with their parents were less likely to develop PTSD following terrorism.

Children with disabilities may manifest an increase in behavioral or emotional problems post-disaster $\left[44^{\bullet}, 54\right]$ and these changes may also increase parental stress. Parents experiencing distress in disaster can have a compromised capacity to respond to their child's emotional symptoms appropriately [66] or contribute to the maintenance of children's post-traumatic stress [37]. In addition, PTSD can be aggravated by caregiver distress when adults are too overwhelmed to satiate children's needs [58, 68, 69].

\section{Family Psychological Treatments}

TF-CBT is typically used as a conjoint child and parent psychotherapy approach. Family-focused CBT was found to be more effective than child-focused CBT in reducing PTSD symptoms in one study which compared a child-focused to a family-focused version of the therapy [70]. In addition, parent-involved intervention shows greater effect size [71], and interventions at the family level are particularly effective in families indicating high levels of PTSD symptoms [69]. Parents can also assist with implementation of CBT methods that clinicians design for their children [60]. Children with disabilities generally rely on family members for health and safety supports to a greater degree [31], thus family interventions may be particularly appropriate.

Schools and school personnel can be instrumental in supporting family interventions [60] and evidenced-based interventions often take place in schools post-disaster [72]. One study found mothers' participation in ongoing therapeutic grief support led to opportunities for increased therapeutic and school support for children with learning disabilities [52॰]. However, families with children with disabilities face numerous logistical barriers post-disaster $[34,73]$ which clinicians should consider when selecting treatment locations. For example, some school counseling spaces may not be accessible to family members using wheelchairs, which may influence involvement in therapies.

\section{School and Teacher Factors}

Children who miss school as a consequence of disaster or terrorism may experience new or additional academic difficulties [72], and children with disabilities may be particularly vulnerable to disruptions in special educational services [11••]. For example, students with significant disabilities demonstrated regression in meeting academic and behavioral goals while out of school for 3 weeks after Hurricane Ike [53•]. In addition, a population-based survey conducted in Port-au-Prince found children with disabilities significantly less likely to be enrolled in school after the 2010 Haitian earthquake [74].

\section{School as Setting for Disaster Mental Health Services}

Schools are ideal settings for providing emergency mental health services as teachers and other school personnel understand developmental issues critical to working with children $[72,75]$. Teachers can provide input on pre-disaster/terrorism functioning as well as help assess child functioning levels in the aftermath of disaster or terrorism [72]. Such information is particularly critical in assessing, diagnosing, and selecting appropriate interventions for children with disabilities, who may not exhibit the same post-disaster/terrorism behaviors as their peers. Schools also can provide referrals to community mental health services or social services which serve families postdisaster/terrorism.

\section{Role of Special Education Teachers}

Special education teachers are instrumental team members during crisis situations [76]. Children with disabilities reported feeling safe with their special education teacher during one disaster [77•]. Special education teachers can also provide effective emotional support to children with pre-existing disabilities impacted by disaster [52•, 53•]. For example, Christ and Christ [52•] reported that grieving students with learning disabilities received interventions more quickly due to the attentions of special educators. Ducy and Stough [53•] found special education teachers offered parents guidance for making sheltering experiences less stressful for their children with disabilities. However, special education teachers often live in the same communities as do their students and their ability to 
address the needs of students with disabilities may be influenced by their own trauma and post-disaster functioning $[11 \bullet$, 56 ]. In addition, essential classroom supplies may be lost or damaged in disaster and hamper teachers from meeting the functional and academic needs of students with disabilities [53•].

\section{Role of School Mental Health Professionals}

School mental health professionals are instrumental to children post-disaster/terrorism given their expertise and training in responding to trauma in the school setting. However, children with disabilities may need specialized assistance when coping and recovering from trauma. For example, children with developmental disabilities may require concrete explanations, visual supports, and repeated explanations of the traumatic event [54]. Collaboration between mental health professionals and teachers can be instrumental in supporting children with disabilities [52•,78]. However, there is a lack of empirical research on how to appropriately modify interventions for students with disabilities impacted by trauma.

\section{Social and Community Factors}

\section{Secondary Adversities}

Children with disabilities have unique support needs which affect physical well-being following disaster or terroristic acts. For instance, many families of children with physical disabilities frequently live in homes adapted to provide barrier-free entry and mobility. In the post-disaster/terrorism landscape, temporary shelters or housing may not accommodate the needs of people with disabilities [4, 34, 79]. For children with medical support needs, the destruction of health care facilities and temporary shortages in electrical power may compound chronic disabilities [80]. Children who use durable medical equipment, such as walkers, wheelchairs, or hearing aids, or who require medical supports also may be differentially at-risk post-disaster/terrorism when these supports are lost or discontinued [81]. Results from one study indicated that children with chronic disabilities might live in more stressful environments postdisaster: They were more likely to miss a medical visit, run out of medications, live with flood or mold damage, or experience disruption in health care [45•]. In addition, alerting devices, educational supplies, communication devices, and adapted computers may be lost and take time for families to replace [53•]. Facing adversities such as these may, in turn, contribute to the psychological stress that children with disabilities and their families experience post-disaster/terrorism [11••].

\section{Displacement Post-Disaster/Terrorism}

Children who relocate to new communities after a disaster face significant challenges [82] and relocation can be particular challenging for children with disabilities and their families, given their reliance on multiple school and community supports. Families of children with autism reported significant changes to their support networks and services after relocating after the L'Aquila, Italy earthquake [56•]. Adults with intellectual disabilities who relocated after Hurricane Katrina reported significant barriers to their long-term recovery, including medical, transportation, and financial needs [4]. Displacement after disaster can also decrease social opportunities [82]. Adults with visual disabilities reported a higher level of social isolation following an earthquake [79]. Children with disabilities often have limited peer friendships and experience loneliness at higher rates than their peers, in part, due to differences in social skills $[83,84]$, making both the loss of old peers and the obtaining of new friends difficult for some children with disabilities.

\section{Other Considerations}

\section{Disasters, Terrorism, and War Create New Incidences of Disability}

Disasters, terrorism, and war all can create new incidences of physical, sensory, and cognitive disability [43]. During the 2008 Sichuan earthquake, it is estimated that over 500 students who were in schools which collapsed during the disaster acquired disabilities [69]. During wartime, landmines are a major cause of death, amputations, and head injuries in children, and continue to contribute to disability incidence when not removed following conflicts [31]. In some parts of the world, disasters can be a major cause of disability: For example, nearly $10 \%$ of people living in the earthquake-prone area of Sakarya, Turkey, reported acquiring a disability as a result of an earthquake [85]. Mental health personnel should be aware of the psychological impact that acquiring a disability has for children and their families.

\section{Stigma and Disability}

Individuals with disabilities experience considerable societal stigma [86]. During disaster and other emergencies, children with disabilities and their families consistently experience barriers, social distancing, and institutional exclusion due to their disability status $[11 \bullet \bullet, 87]$. Among disability groups, families of individuals with psychiatric disabilities are particularly stigmatized [88]. Families may avoid seeking help from mental 
health professionals following disaster or terroristic exposures to prevent additional stigmatization. Locating mental health services in school facilities post-disaster/terrorism may help normalize and lessen stigma surrounding psychological treatment.

\section{Importance of Preparedness to Decrease Exposure to Disasters and Terrorism}

Emergency preparedness education is needed to increase the resiliency of children with disabilities to disaster and terrorism $[10,12 \bullet \bullet, 31]$. Several studies $[41,44,89]$ report parents of children with disabilities as underprepared with respect to supplies, planning, and knowledge needed during emergencies. Several recent studies, however, have documented successful disaster preparedness interventions with parents of children with disabilities [41, 89, 90]. Children with disabilities are often not included in emergency planning or training, which can also increase their level of vulnerability when away

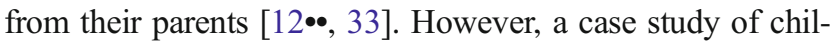
dren with disabilities who had first-hand experience of the 2010 Canterbury earthquakes found they had overall good awareness and understanding of potential hazards as well as the ability to participate in emergency preparedness [77•]. In addition to individual preparedness measures, inequitable societal conditions which exist in advance of emergencies must be mitigated to decrease the overall exposure of individuals with disabilities to hazards [91].

\section{Conclusion and Future Directions}

Empirical research on children with disabilities exposed to disaster or terrorism is extremely limited and much work remains to be done in this area. First, while most children are psychologically resilient and do not develop psychopathology following disaster or terrorism [36], we know little about the resiliency of children with disabilities under the same circumstances. Second, the mental health of individuals with disabilities post-disaster/terrorism has been substantially overlooked by both researchers and clinicians [39]. The lack of attention to trauma treatment in children with disabilities is particularly alarming, and empirically verified interventions which have been appropriately modified for this population are sorely needed. Third, almost all studies of children with disabilities in disaster or terrorist situations rely exclusively on parental or caregiver reports. While investigations using first person accounts from adults with disabilities have been conducted [43, 92], similar studies with children with disabilities are needed. Finally, substantial societal changes are needed to reduce the disproportionate environmental and social vulnerability of children with disabilities to disasters and terrorism [91].

\section{Compliance with Ethical Standards}

Conflict of Interest Laura M. Stough, Elizabeth McAdams Ducy, and Donghyun Kang declare that they have no conflict of interest.

Human and Animal Rights and Informed Consent This article does not contain any studies with human or animal subjects performed by any of the authors.

\section{References}

Papers of particular interest, published recently, have been highlighted as:

- Of importance

•• Of major importance

1. Brittingham $R$, Wachtendorf $T$. The effect of situated access on people with disabilities: an examination of sheltering and temporary housing after the 2011 Japan earthquake and tsunami. Earthquake Spectra. 2013;29:S433.

2. Eisenman DP, Zhou Q, Ong M, Asch S, Glik D, Long A. Variations in disaster preparedness by mental health, perceived general health, and disability status. Disaster Medicine and Public Health Preparedness. 2009;3(1):33-41.

3. Good G, Phibbs S, Williamson K. Disoriented and immobile: the experiences of people with visual impairments during and after the Christchurch, New Zealand, 2010 and 2011 earthquakes. Journal Of Visual Impairment \& Blindness. 2016;110(6):425-35.

4. Stough L, Sharp A, Resch J, Decker C, Wilker N. Barriers to the long-term recovery of individuals with disabilities following a disaster. Disasters. 2015;40(3):387-410.

5. Chou Y, Huang N, Lee C, Tsai S, Chen L, Chang H. Who is at risk of death in an earthquake? Am J Epidemiol. 2004;160(7):688-95.

6. Osaki Y, Minowa M. Factors associated with earthquake deaths in the Great Hanshin-Awaji Earthquake, 1995. Am J Epidemiol. 2001;153(2):153-6.

7. Becker-Blease K, Turner H, Finkelhor D. Disasters, victimization, and children's mental health. Child Dev. 2010;81(4):1040-52.

8. Hoven CW, Duarte CS, Lucas CP, Wu P, Mandell DJ, Goodwin RD, Cohen M, Balaban V, Woodruff BA, Bin F, Musa GJ. Psychopathology among New York City public school children 6 months after September 11. Arch Gen Psychiatry. 2005;62(5):54551.

9. Norris FH, Friedman MJ, Watson PJ. 60,000 disaster victims speak: part II. Summary and implications of the disaster mental health research. Psychiatry: Interpersonal and Biological Processes. 2002;65(3):240-60.

10. Phillips BK, Stough LM. Populations with functional or access needs. K. Koenig and C. Schulz. Disaster medicine. 2016:137-62.

11.• Peek L, Stough LM. Children with disabilities in the context of disaster: a social vulnerability perspective. Child Dev. 2010;81(4): 1260-70. This paper reviewed disaster research both on children and on adults with disabilities and provided a framework for understanding how children with disabilities are subject to a clustering of vulnerabilities in the disaster context.

12.• Ronoh S, Gaillard JC, Marlowe J. Children with disabilities and disaster risk reduction: a review. International Journal of Disaster Risk Science. 2015;6(1):38-48. This paper highlighted existing research on individuals with disabilities and proposed a role for children with disabilities in disaster risk reduction. 
13. American Psychiatric Association. Diagnostic and statistical manual of mental disorders (DSM-5®). American Psychiatric Pub; 2013.

14. World Health Organization. International Classification of Functioning, Disability and health: ICF. World Health Organization; 2001.

15. World Health Organization. World report on disability. World Health Organization; 2011.

16. Batavia AI, Beaulaurier RL. The financial vulnerability of people with disabilities: assessing poverty risks. J Soc \& Soc Welfare. 2001;28:139.

17. Mitra S, Posarac A, Vick BC. Disability and poverty in developing countries: a snapshot from the World Health Survey. Cornell University ILR School. 2011.

18. Masten AS, Osofsky JD. Disasters and their impact on child development: introduction to the special section. Child Dev. 2010;81(4): 1029-39.

19. Furr JM, Comer JS, Edmunds JM, Kendall PC. Disasters and youth: a meta-analytic examination of posttraumatic stress. J Consult Clin Psychol. 2010;78(6):765-80.

20. Masten AS, Narayan AJ. Child development in the context of disaster, war, and terrorism: pathways of risk and resilience. Annu Rev Psychol. 2012;63:227-57.

21. Scheeringa MS. Untangling psychiatric comorbidity in young children who experienced single, repeated, or Hurricane Katrina traumatic events. Child Youth Care Forum. 2015;44(4):475-92.

22. Weems CF, Graham RA. Resilience and trajectories of posttraumatic stress among youth exposed to disaster. Journal of Child and Adolescent Psychopharmacology. 2014;24(1):2-8.

23. National Organization on Disability. Report on special needs assessment for Katrina evacuees (SNAKE) Project. National Organization on Disability; 2005.

24. Kailes JI. Southern California wildfires after action report. Center for Disability Issues and the Health Professions, 2008.

25. Rooney C, White GW. Consumer perspective narrative analysis of a disaster preparedness and emergency response survey from persons with mobility impairments. Journal of Disability Policy Studies. 2007;17(4):206-1.

26. Stough LM, Sharp AN, Decker C, Wilker N. Disaster case management and individuals with disabilities. Rehabilitation Psychology. 2010;55(3):211.

27. Charlton M, Kliethermes M, Tallant B, Taverne A, Tishelman A. Facts on traumatic stress and children with developmental disabilities. National Child Traumatic Stress Network: Adapted Trauma Treatment Standards Work Group, 2004.

28. Saylor CF, Macias M, Wohlfeiler M, Morgan L, Awkerman NG. Exposure to potentially traumatic life events in children with special needs. Child Psychiatry Hum Dev. 2009;40(3):451-65.

29. Pfefferbaum B, Jacobs AK, Houston JB, Griffin N. Children's disaster reactions: the influence of family and social factors. Current Psychiatry Reports. 2015;17(7):1-6.

30. Emerson E, Hatton C. Poverty, socio-economic position, social capital and the health of children and adolescents with intellectual disabilities in Britain: a replication. J Intellect Disabil Res. 2007;51(11):866-74.

31. UNICEF. The state of the world's children: children with disabilities. UN; 2013.

32. Mitchell D, Karr V. Crises, conflict and disability: ensuring equality. Routledge; 2014.

33. Boon HJ, Brown LH, Tsey K, Speare R, Pagliano P, Usher K, Clark B. School disaster planning for children with disabilities: a critical review of the literature. International Journal of Special Education. 2011;26(3):223-37.

34. Twigg J, Kett M, Bottomley H, Tan LT, Nasreddin H. Disability and public shelter in emergencies. Environmental Hazards. 2011;10(34):248-61.
35. Pfefferbaum B, Noffsinger MA, Jacobs AK, Varma V. Children's cognitive functioning in disasters and terrorism. Current Psychiatry Reports. 2016;18(5):48.

36. Pfefferbaum B, Jacobs AK, Griffin N, Houston JB. Children's disaster reactions: the influence of exposure and personal characteristics. Current Psychiatry Reports. 2015;17(7):56. doi:10.1007/ s11920-015-0598-5.

37. Jensen TK, Dyb G, Nygaard E. A longitudinal study of posttraumatic stress reactions in Norwegian children and adolescents exposed to the 2004 tsunami. Archives Of Pediatrics \& Adolescent Medicine. 2009;163(9):856-61.

38. La Greca AM, Silverman WK, Lai B, Jaccard J. Hurricane-related exposure experiences and stressors, other life events, and social support: concurrent and prospective impact on children's persistent posttraumatic stress symptoms. J Consult Clin Psychol. 2010;78(6): 794.

39. Stough LM. The effects of disaster on the mental health of individuals with disabilities. In: Neria Y, Galea S, Norris FM, editors. Mental health and disasters. New York: Cambridge University Press; 2009. This review of the literature examined findings on the effects of disaster on individuals with preexisting cognitive, physical, sensory, or mental health disabilities.

40. Baker LR, Baker MD. Disaster preparedness among families of children with special health care needs. Disaster Medicine and Public Health Preparedness. 2010;4(03):240-5.

41. Wolf-Fordham S, Curtin C, Maslin M, Bandini L, Hamad CD. Emergency preparedness of families of children with developmental disabilities: what public health and safety emergency planners need to know. Journal of Emergency Management (Weston, Mass). 2015;13(1):7.

42. Gershon RR, Kraus LE, Raveis VH, Sherman MF, Kailes JI. Emergency preparedness in a sample of persons with disabilities. Am J Disaster Med. 2013;8(1):35-47.

43. Kelman I, Stough LM. Exploring and exchanging (dis)ability and (dis)aster. Disability and Disaster. 2015.

44. Baker LR, Cormier LA. Disaster preparedness and families of children with special needs: a geographic comparison. J Community Health. 2013;38(1):106-12.

45. Rath B, Donato J, Duggan A, Perrin K, Bronfin DR, Ratard R, VanDyke R, Magnus M. Adverse health outcomes after Hurricane Katrina among children and adolescents with chronic conditions. J Health Care Poor Underserved. 2007;18(2):405-17. This study evaluated differences between children and adolescents with and without chronic health conditions immediately following Hurricane Katrina.

46. Brodie M, Weltzien E, Altman D, Blendon RJ, Benson JM. Experiences of Hurricane Katrina evacuees in Houston shelters: implications for future planning. Am J Public Health. 2006;96(8): 1402-8.

47. Barile M, Fichten C, Ferraro V, Judd D. Ice storm experiences of persons with disabilities: knowledge is safety. Review of Disability Studies. 2006;2(3):35-48.

48. White B. Disaster relief for deaf persons: lessons from Hurricanes Katrina and Rita. Review of Disability Studies: An International Journal. 2014:2(3).

49. Mehtar M, Mukaddes NM. Posttraumatic stress disorder in individuals with diagnosis of autistic spectrum disorders. Research in Autism Spectrum Disorders. 2011;5(1):539-46. This study examined the trauma history of children and adolescents diagnosed with both autism and PTSD.

50. Finzi-Dottan R, Dekel R, Lavi T, Su'ali T. Posttraumatic stress disorder reactions among children with learning disabilities exposed to terror attacks. Compr Psychiatry. 2006;47(2):144-51.4. This study examined PTSD reactions in adolescents with learning disabilities who were exposed to terror attacks. 
51. Fletcher RJ, Barnhill J, McCarthy J, Strydom A. From DSM to DM-ID. J Ment Health Res Intellect Disabil. 2016;9(3):189-204.

52. Christ GH, Christ TW. Academic and behavioral reactions of children with disabilities to the loss of a firefighter father: The New York City World Trade Center Attack 9/11/01. The Review of Disability Studies: An International Journal. 2006;2(3):68-78. This paper provides detailed case studies of children with learning disabilities receiving clinical therapy following the loss of their fathers as a result of the 9/11 attacks in New York.

53. Ducy EM, Stough LM. Exploring the support role of special education teachers after Hurricane Ike: children with significant disabilities. J Fam Issues. 2011;32(10):1325-45. This study examines the actions and responses of teachers of students with disabilities during and after their evacuation from Hurricane Ike.

54. Sormanti M, Ballan MS. Strengthening grief support for children with developmental disabilities. Sch Psychol Int. 2011;32(2):17993.

55. Durkin MS, Khan N, Davidson LL, Zaman SS, Stein ZA. The effects of a natural disaster on child behavior: evidence for posttraumatic stress. Am J Public Health. 1993;3(11):1549-53. This study examined increases in behavioral problems, specifically aggression and enuresis, in children with disabilities following the 1988 Bangladesh flood.

56. Valenti M, Ciprietti T, Di Egidio C, Gabrielli M, Masedu F, Tomassini AR, Sorge G. Adaptive response of children and adolescents with autism to the 2009 earthquake in L'Aquila, Italy. J Autism Dev Disord. 2012;42(6):954-60. This study evaluated the adaptive behavior of participants with autism following exposure to an earthquake.

57. Brickell C, Munir K. Grief and its complications in individuals with intellectual disability. Harvard Review of Psychiatry. 2008;16(1):1-2.

58. Schneider SJ, Grilli SF, Schneider JR. Evidence-based treatments for traumatized children and adolescents. Current Psychiatry Reports. 2013;15(1):332.

59. Ramirez de Arellano MA, Lyman DR, Jobe-Shields L, George P, Dougherty RH, Daniels AS, Ghose SS, Huang L, Delphin-Rittmon ME. Trauma-focused cognitive-behavioral therapy for children and adolescents: assessing the evidence. Psychiatr Serv. 2014;65(5): 591-602.

60. Walters S, Loades M, Russell A. A systematic review of effective modifications to cognitive behavioural therapy for young people with autism spectrum disorders. Review Journal of Autism and Developmental Disorders. 2016;3(2):137-53.

61. Mevissen L, De Jongh A. PTSD and its treatment in people with intellectual disabilities: a review of the literature. Clin Psychol Rev. 2010;30(3):308-16.

62. Unwin G, Tsimopoulou I, Kroese BS, Azmi S. Effectiveness of cognitive behavioural therapy (CBT) programmes for anxiety or depression in adults with intellectual disabilities: a review of the literature. Res Dev Disabil. 2016;51:60-75.

63. Stott J, Charlesworth G, Scior K. Measures of readiness for cognitive behavioural therapy in people with intellectual disability: a systematic review. Res Dev Disabil. 2017;60:37-51.

64. Brown JF, Brown MZ, Dibiasio P. Treating individuals with intellectual disabilities and challenging behaviors with adapted dialectical behavior therapy. J Ment Health Res Intellect Disabil. 2013;6(4):280-303.

65. Pfefferbaum B, North CS. Child disaster mental health services: a review of the system of care, assessment approaches, and evidence base for intervention. Current Psychiatry Reports. 2016;18(1):5.

66. Cobham V, McDermott B, Haslam D, Sanders M, Cobham VE, Sanders MR. The role of parents, parenting and the family environment in children's post-disaster mental health. Current Psychiatry Reports. 2016;18(6):1-9.

67. Miranda A, Tárraga R, Fernández MI, Colomer C, Pastor G. Parenting stress in families of children with autism spectrum disorder and ADHD. Except Child. 2015;82(1):81-95. doi:10. $1177 / 0014402915585479$.

68. Lambert JE, Holzer J, Hasbun A. Association between parents' PTSD severity and children's psychological distress: a meta-analysis. J Trauma Stress. 2014;27(1):9-17. doi:10.1002/jts.21891.

69. Polusny MA, Ries BJ, Meis LA, DeGarmo D, McCormick-Deaton $\mathrm{CM}$, Thuras P, et al. Effects of parents' experiential avoidance and PTSD on adolescent disaster-related posttraumatic stress symptomatology. J Fam Psychol. 2011;25(2):220-9.

70. Kenardy J, Cobham V, Nixon RDV, McDermott B, March S. Protocol for a randomised controlled trial of risk screening and early intervention comparing child- and family-focused cognitivebehavioural therapy for PTSD in children following accidental injury. BMC Psychiatry. 2010:10(92). doi:10.1186/1471-244x-1092.

71. Newman E, Pfefferbaum B, Kirlic N, Tett R, Nelson S, Liles B. Meta-analytic review of psychological interventions for children survivors of natural and man-made disasters. Current Psychiatry Reports. 2014:16(9). Doi:10.1007/s11920-014-0462-z.

72. Lai BS, Esnard AM, Lowe SR, Peek L. Schools and disasters: safety and mental health assessment and interventions for children. Current Psychiatry Reports. 2016;18(12):109.

73. Stough, L. M., Ducy, E. M., and Holt, J. M. Changes in the social relationships of individuals with disabilities displaced by disaster (in review).

74. Danquah L, Polack S, Brus A, Mactaggart I, Houdon CP, Senia P, Gallien P, Kuper H. Disability in post-earthquake Haiti: prevalence and inequality in access to services. Disabil Rehabil. 2015;37(12): 1082-9.

75. Pfefferbaum B, Pfefferbaum RL, Gurwitch RH, Nagumalli S, Brandt Jr EN, Robertson MJ, et al. Children's response to terrorism: a critical review of the literature. Current Psychiatry Reports. 2003;5(2):95-100.

76. Clarke LS, Embury DC, Jones RE, Yssel N. Supporting students with disabilities during school crises: a teacher's guide. Teach Except Child. 2014;46(6):169-78.

77. Ronoh S, Gaillard JC, Marlowe J. Children with disabilities and disaster preparedness: a case study of Christchurch. Kōtuitui: New Zealand Journal of Social Sciences Online. 2015:10(2):91-102. This case study examined knowledge about disaster and emergency preparedness in children who experience the 2010 Canterbury earthquakes.

78. Wong JH. Psychosocial recovery for children disabled in an earthquake: school social work in Dujiangyan, China. Journal of Social Work in Disability \& Rehabilitation. 2013;12(1-2):102-15.

79. Phibbs S, Good G, Severinsen C, Woodbury E, Williamson K. What about us? Reported experiences of disabled people related to the Christchurch earthquakes. Procedia Economics and Finance. 2014;18:190-7.

80. Sakashita K, Matthews WJ, Yamamoto LG. Disaster preparedness for technology-and electricity-dependent children and youth with special health care needs. Clin Pediatrics. 2013.

81. Stough LM, Mayhorn C. Population segments with disabilities. Journal of Mass Emergencies and Disasters. 2013;31(3):384-402.

82. Pfefferbaum B, Jacobs AK, Van Horn RL, Houston JB. Effects of displacement in children exposed to disasters. Current Psychiatry Reports. 2016;18(8):1-5.

83. Gilmore L, Cuskelly M. Vulnerability to loneliness in people with intellectual disability: an explanatory model. Journal of Policy and Practice in Intellectual Disabilities. 2014;11(3):192-9.

84. Petrina N, Carter M, Stephenson J. The nature of friendship in children with autism spectrum disorders: a systematic review. Research in Autism Spectrum Disorders. 2014;8(2):111-26.

85. Karatas K, Duyan V. Self-esteem and trait-anxiety levels of persons with physical disabilities who live in the earthquake region. Int J Ment Health. 2004;33(1):67-80. 
86. Smart JF. Disability, society, and the individual. Pro Ed: TX; 2008.

87. Priestley M, Hemingway L. Disability and disaster recovery: a tale of two cities? Journal of Social Work in Disability \& Rehabilitation. 2007;5(3-4):23-42.

88. Nguyen-Finn K. History of treatment towards persons with psychiatric disabilities. In: Marini I, A Stebnicki M, editors. The psychological and social impact of illness and disability. New York: Springer; 2012.

89. Baker MD, Baker LR, Flagg LA. Preparing families of children with special health care needs for disasters: an education intervention. Soc Work Health Care. 2012;51(5):417-29.
90. Bagwell HB, Liggin R, Thompson T, Lyle K, Anthony A, Baltz M, Melguizo-Castro M, Nick T, Kuo DZ. Disaster preparedness in families with children with special health care needs. Clin Pediatr. 2016;55(11):1036-43.

91. Stough LM, Kang D. The Sendai framework for disaster risk reduction and persons with disabilities. International Journal of Disaster Risk Science. 2015;6(2):140-9.

92. Ducy E, Stough LM, Clark MC. Choosing agency in the midst of vulnerability: Using critical disability theory to examine a disaster narrative. S. Steinberg and G. Canella. Critical Qualitative Research Reader. 2012:307-17. 